\title{
Cold-Induced Ascites in Broilers: Effects of Vitamin C and Coenzyme $Q_{10}$
}

\section{-Author(s)}

\section{Nemati $\mathrm{MH}^{\prime}$ \\ Shahir $\mathrm{MH}^{\mathrm{\prime}}$ \\ Harakinezhad MT' \\ Lotfalhian $\mathrm{H}^{\prime}$}

Department of Animal Science, Zanjan Agriculture and Natural Resource Research and Education Center, AREEO, Zanjan, Iran

\section{Mail Address}

Corresponding author e-mail address Mohammad Hossein Nemati

Department of Animal Science, Zanjan Agricultur and Natural Resource research and Education Center, AREEO, Zanjan, Iran

Tel: $\quad 00982433026123$

Email: nemati.mh1354@gmail.com

\section{EKeywords}

Ascites, broiler, coenzyme Q10, cold stress, vitamin $\mathrm{C}$.

\section{ABSTRACT}

We hypothesized that the supplementation of vitamin C (Vit. C) and coenzyme $\mathrm{Q}_{10}\left(\mathrm{CoQ}_{10}\right)$ alone or in combination could reduce the negative effects of cold stress in broilers. Four hundred male chicks were exposed for $24 \mathrm{~h}$ to cold stress $\left(15^{\circ} \mathrm{C}\right)$ starting from $15 \mathrm{~d}$ of age, while a positive control group (PC, 100 birds) was kept under normal temperature condition. The experimental groups under cold stress (four treatments in 5 replicates of 20 birds) were: negative control (NC, basal diet), Vit. C (basal diet $+300 \mathrm{mg} / \mathrm{kg}$ Vit. C), $\mathrm{CoQ}_{10}$ (basal diet $+40 \mathrm{mg} / \mathrm{kg} \mathrm{CoQ}{ }_{10}$ ) and Vit. C plus $\mathrm{CoQ}_{10}$ (basal diet + Vit. C+CoQ 10 at above mentioned doses). Vit. $C$ or $\mathrm{CoQ}_{10}$ supplementation were restored $(p<0.01)$ performance and lowered $(p<0.01)$ ascites mortality. Blood hematocrit and hemoglobin concentration were decreased $(p<0.01)$ to the level comparable to PC by Vit. $C$ supplementation. Lower plasma concentrations of thyroxin $\left(T_{4}\right)$ and higher triiodothyronine $\left(T_{3}\right)$ were observed in NC birds $(p<0.01)$ and were not affected by Vit. $\mathrm{C}$ or $\mathrm{CoQ}_{10}$. In conclusion, supplementation of Vit. $\mathrm{C}$ or $\mathrm{CoQ}_{10}$ in diet of broilers under cold stress conditions resulted improved performance parameters (body weight and feed conversion ratio) and ascites related traits (low red blood cell count, hematocrit, $T_{3 \prime}$ and heart weights and high $\mathrm{T}_{4}$ ). No additional benefit was observed by combination of Vit. C and CoQ10.

\section{INTRODUCTION}

The rapid growth of modern broilers in a relatively short period of time requires a parallel increase in the size or capacity of supply organs, such as those of the cardiovascular and respiratory systems. However, due to the slower development of these organs relative to body growth rate, the capacity to balance body energy is compromised, particularly under extreme environment conditions, such as cold stress (Shahir et al., 2012; Shinder, 2002).

Cold environmental temperatures tend to increase blood triiodothyronine $\left(T_{3}\right)$ levels, required for the generation of additional metabolic heat to maintain body temperature in colder environments. The subsequent increase in basal metabolic rate results in an increase in oxygen demand and the heart attempts to maintain oxygen supply to the organs and muscles, thus chronically leading to pulmonary hypertension syndrome (PHS), right ventricular hypertrophy, ascites or water belly, and eventually death (Gupta, 2011).

According to Currie (1999) the main reasons of the etiology of ascites could be classified as: pulmonary hypertension, cardiac pathologies, and cellular damage due to oxidative stress caused by increased reactive oxygen species (ROS) production. Enkvetchakul et al. (1993) verified that chickens with ascites suffered from high oxidative stress. Mitochondrial electron leak and ROS production are increased during hypoxia and ascites (Dawson et al., 1993). Tang et al. (2002) also 
Cold-Induced Ascites in Broilers: Effects of Vitamin C and Coenzyme $Q_{10}$ reported high electron leakage in the mitochondria of heart of broilers developing ascites.

As a result of oxidative stress, major antioxidants, such as glutathione, $\alpha$-tocopherol, and ascorbic acid are reduced in the liver and the lungs of broilers with PHS (Enkvetchakul et al., 1993; Bottje \& Wideman, 1995). Vitamin E (Vit. E), vitamin C (Vit. C), coenzyme $\mathrm{Q}(\mathrm{CoQ})$, and other antioxidants have beneficial effects as they scavenge free radicals (Gupta, 2011, Ruiz -Feria, 2009). Vit. C at 500 ppm reduced mortality due to PHS induced by cold environmental temperatures (Hassnzadeh et al., 1997). The supplementation of Vit. C at 150 to $450 \mathrm{ppm}$ was also shown to reduce the incidence of ascites caused by feeding extremely high dietary levels of $\mathrm{NaCl}$ to broilers (AlTaweil \& Kassab, 1990). Broilers submitted to heat stress and supplemented with Vit. C presented better performance, as well as lower plasma corticosterone and higher thyroid hormone levels compared with non-supplemented birds (McKee et al., 1997).

Coenzyme $\mathrm{Q}_{10}\left(\mathrm{CoQ}_{10}\right)$ is an essential component of the respiratory chain in the inner mitochondrial membrane, and functions as an electron and proton carrier, stimulating ATP synthesis. In addition, its reduced form - $\mathrm{CoQH}_{2}$ (ubiquinol) - can act as an important antioxidant, lowering the accumulation of free radicals, particularly of ROS, thereby reducing peroxidative damage to the body (Forsmark-Andrée et al., 1997). Nakamura (1996) fed diets supplemented with coenzyme $\mathrm{Q}_{9}$, an analogue of $\mathrm{CoQ}_{10}$, at $40 \mathrm{mg} /$ $\mathrm{kg}$ to broiler chicks and showed that dietary coenzyme $\mathrm{Q}_{9}$ supplementation reduced the incidence of ascites.

We hypothesized that $\mathrm{CoQ}_{10}$ and Vit. C supplementation to broilers could alleviate the negative effects of cold stress at mitochondrial and cytosolic level, respectively. To the authors' knowledge, there is no information on the combined effects of the supplementation of Vit. $C$ and $\mathrm{CoQ}_{10}$ on the performance, blood biochemical parameters, and incidence of ascites of broiler chickens reared under ascites-inducing condition.

\section{MATERIALS AND METHODS}

Five hundred male broiler chicks (Hybro) were placed in two environmentally-controlled houses on floor pens $(1.3 \mathrm{~m} \times 3 \mathrm{~m})$ on the day of hatch. Birds were distributed according in a completely randomized design with five treatments, with five replicates (pens) of 20 birds each. The treatments included: positive control ( $\mathrm{PC}$, normal rearing conditions and no antioxidant supplementation), negative control (NC, cold stress and no antioxidant supplementation), or cold stress and supplementation of Vit. C (NC+Vit. C, $300 \mathrm{mg} / \mathrm{kg}$ of ascorbic acid, DSM), CoQ 10 (NC+ CoQ 10 , $40 \mathrm{mg} / \mathrm{kg}$ of coenzyme Q10 provided by Summit AGRO International Ltd., Japan), or Vit. C $+\mathrm{CoQ}_{10}(\mathrm{NC}+$ Vit. $\mathrm{C}+\mathrm{CoQ}_{10}$, combination of both antioxidants at the same levels). To induce ascites, cold stress started from $15 \mathrm{~d}$ of age to the end of experiment, time of exposed $24 \mathrm{~h}$. The starter (0-14d), grower (14-28d), and finisher (28$42 \mathrm{~d}$ ) experimental diets were mixed in single batches (Table 1). The experimental procedures were approved by the Animal Science Research Institution.

Table $\mathbf{1}$ - Ingredients and chemical composition of the basal diet

\begin{tabular}{|c|c|c|c|}
\hline Ingredient (g/kg) & $\begin{array}{l}\text { Starter } \\
(0-14 d)\end{array}$ & $\begin{array}{c}\text { Grower } \\
(14-28 d)\end{array}$ & $\begin{array}{l}\text { Finisher } \\
(28-42 d)\end{array}$ \\
\hline Corn grain & 532 & 565.2 & 643.8 \\
\hline Soybean meal & 394 & 360.5 & 290.2 \\
\hline Soybean oil & 31.2 & 33.6 & 27.2 \\
\hline Dicalcium phosphate & 19 & 17.5 & 16 \\
\hline Calcium carbonate & 11 & 11 & 10 \\
\hline Salt(lodized) & 3.6 & 3.3 & 3.4 \\
\hline Vitamin premix ${ }^{1}$ & 3 & 3 & 3 \\
\hline Mineral premix ${ }^{2}$ & 3 & 3 & 3 \\
\hline DL-Methionine & 2.2 & 1.9 & 2.1 \\
\hline L-lysine hydrochloride & 1 & 1 & 1.3 \\
\hline \multicolumn{4}{|l|}{ Analyzed composition } \\
\hline Metabolizable energy (Kcal/kg) & 2950 & 3000 & 3000 \\
\hline Crude protein $(\mathrm{g} / \mathrm{kg})$ & 221.8 & 209.5 & 187.5 \\
\hline Calcium $(\mathrm{g} / \mathrm{kg})$ & 10 & 9.5 & 9 \\
\hline Available Phosphorus (g/kg) & 5 & 4.75 & 4 \\
\hline Sodium $(\mathrm{g} / \mathrm{kg})$ & 1.7 & 1.6 & 1.6 \\
\hline Lysine $(\mathrm{g} / \mathrm{kg})$ & 13 & 12 & 11 \\
\hline Arginine (g/kg) & 15.5 & 14.6 & 12.7 \\
\hline Methionine $(\mathrm{g} / \mathrm{kg})$ & 5.8 & 5.4 & 5.2 \\
\hline Methionine +Cyst(e)ine (g/kg) & 9.3 & 8.7 & 8.2 \\
\hline
\end{tabular}

'Supplied per kg of diet: all-trans retinyl acetate, 3.7mg; cholecalciferol 0.06 mg; $\mathrm{DL}$ - $\alpha$-tocopheryl acetate, $16.4 \mathrm{mg}$; menadione (as menadione sodium bisulfate), 2.4 $\mathrm{mg}$; thiamine (as thiamine hydrochloride), $2 \mathrm{mg}$; riboflavin, 7.9 mg; niacin, $11.7 \mathrm{mg}$; pantothenic, $35.6 \mathrm{mg}$; pyridoxine, $3.5 \mathrm{mg}$; folic acid, $1.2 \mathrm{mg}$; biotin, $0.12 \mathrm{mg}$; cyanocobalamin, $0.02 \mathrm{mg}$; choline choloride, $300 \mathrm{mg}$; antioxidant, $1.2 \mathrm{mg}$.

${ }^{2}$ Supplied per kg of diet:Mn, 48 mg; Zn, 48 mg; Fe, 24 mg; Cu, 7 mg; I, 0.6 mg; Se, $0.15 \mathrm{mg}$.

All broilers were brooded under the temperatures recommended by the genetic company manual (Hybro) until $14 \mathrm{~d}$ of age. The cold-stress protocol of Ruiz-Feria (2009) was applied with slight modifications to promote ascites. Briefly, broilers in the cold-stress groups were subjected between days 15 to 21 to a gradual temperature decline down to $15{ }^{\circ} \mathrm{C}$, which remained constant until day 42, despite slight fluctuations (less than $\pm 2^{\circ} \mathrm{C}$ ). Positive-control birds (100 birds in five replicates) were reared under the 
recommended temperature $\left(23-25^{\circ} \mathrm{C}\right)$ between 21 and 42 days of age. Feed and water were provided ad libitum. A photoperiod of 23L:1D was applied.

\section{Live performance parameters}

Weekly feed intake (FI) and body weight gain (BWG) were measured. Mortality was daily recorded, and the dead birds were weighed and necropsied for the presence of water accumulation in the abdomen, which was considered as ascites. Only the heart of the dead birds with ascites lesions was removed and weighed. The right ventricle (RV) was carefully sectioned, separated from the left ventricle and weighed. The RV:TV (total ventricular) ratio was calculated. At the end of experiment (42 days of age), eight birds per treatment were sacrificed, and their $\mathrm{RV}$ :TV ratios calculated.

\section{bin}

Red blood cells, hematocrit and hemoglo-

At 35 days of age, $2.5 \mathrm{~mL}$ blood samples were collected from the wing vein of five birds per treatment in EDTA-containing tubes. Red blood cells were counted under light hemocytometer. Hematocrit was measured in capillary tubes and hemoglobin concentration was determined by the ICSH method (International Committee for Standardization in Hematology).

\section{Blood biochemical parameters}

At the end of experiment (42 days of age) eight birds per treatment were selected for blood collection, as described above. The serum was separated by centrifugation and used to determine blood biochemical parameters. Thyroid hormone $\left(\mathrm{T}_{4}\right.$ and $\mathrm{T}_{3}$ ) levels were determined by enzyme linked immuno sorbent assay (ELISA) using commercial kits (Monobind Inc., USA).

\section{Statistical analysis}

Data were analyzed according to completely randomized experimental design was applied. Data were analyzed by the general linear model procedure of SAS $^{\circledR}$ software (SAS 9.1, 2003). In the cold stress condition, a $2 \times 2$ factorial arrangement was applied, consisting of the supplementation or not of any of the antioxidants and their levels. The differences among treatments were evaluated by Tukey's test. The following model was applied:

$$
Y_{i j k}=\mu+\alpha_{i}+\beta_{j}+\alpha \beta_{i j}+\varepsilon_{i j k}
$$

Where $Y_{i j k}$ is dependent variable; $\mu$ is the general mean, and $\alpha_{i}$ and $\beta$ are the main effects of Vit. $C$ and
$\mathrm{CoQ}_{10}$, respectively, and $\alpha \beta_{\mathrm{ij}}$ is interaction between the factors. Orthogonal contrasts were applied to compare the results PC vs. NC, PC vs. antioxidant, and NC vs. antioxidant treatment. Mortality data were analyzed by the GENMOD procedure. Probability levels lower than 0.05 were considered significant, unless otherwise noted.

\section{RESULTS}

\section{Live Performance}

The birds fed antioxidants (Vit. C, CoQ ${ }_{10}$ or Vit. $\left.C+C_{0 Q}\right)$ presented higher BWG than the PC birds $(p<0.01)$ during the finisher and total periods. This difference is mainly attributed to dietary Vit. C supplementation $(p<0.05)$. The interaction between Vit. C and $\mathrm{CoQ}_{10}$ showed that Vit. C was only effective when the diet was not supplemented with $\mathrm{CoQ}_{10}(p<0.05)$. There was no difference in $\mathrm{Fl}$ among treatment groups during the different rearing phases, except when PC was contrasted with NC. The worst FCR was determined in the NC $(p<0.01)$ during all evaluated phases, and antioxidant supplementation decreased FCR to levels comparable with the PC treatment. The diet containing only $\mathrm{CoQ}_{10}$ promoted lowest FCR $(p<0.01)$. The interaction between Vit. $C$ and $\mathrm{CoQ}_{10}$ hada significant effect $(p<0.01)$ on FCR during all evaluated phases.

\section{Ascites incidence}

Higher mortality due to ascites $(p<0.01)$ was observed in the NC treatment compared with the other treatments (Table 3). The individual supplementation of Vit. C and CoQ10 reduced the mortality due to ascites, but not their combined supplementation to cold-stressed birds). Although no differences in heart weight were not significant among treatments, the NC birds presented the highest value. The RV/TV ratio was relatively higher in NC birds compared with PC birds $(p<0.05)$, and corresponded to the higher mortality due to ascites in this group.

\section{Red blood cells, packed-cell volume and hemoglobin}

Higher red blood cell counts (RBC), packed-cell volume $(\mathrm{PCV})$, and hemoglobin $(\mathrm{Hb})$ levels were determined in the blood of NC birds compared with the $P C$ and $P C+V i t . C$ groups, but were not different from the $P C+C_{10}$ and the $P C+V i t . C+C_{10}$ groups. The dietary addition of antioxidants reduced both PCVand RBC to the levels comparable with PC. Vit. C addition was quite effective in this regard 
Table 2 - Effect of vitamin $C$ and $\mathrm{CoQ}_{10}$ on growth performance in broilers under cold stress

\begin{tabular}{|c|c|c|c|c|c|c|c|c|c|}
\hline \multirow{2}{*}{ Variable } & \multicolumn{3}{|c|}{ BWG(gr) } & \multicolumn{3}{|c|}{$\mathrm{Fl}(\mathrm{gr})$} & \multicolumn{3}{|c|}{ FCR } \\
\hline & $14-28$ & $28-42$ & $14-42$ & $14-28$ & $28-42$ & $14-42$ & $14-28$ & $28-42$ & $14-42$ \\
\hline PC & 724.8 & $1089 \mathrm{bc}$ & 1814 bc & 1252 & 2475 & 3726 & $1.73^{b}$ & $2.27^{b}$ & $2.05^{b}$ \\
\hline NC & 722.8 & $1010^{c}$ & $1733^{c}$ & 1380 & 2523 & 3902 & $1.90^{\mathrm{a}}$ & $2.50^{a}$ & $2.25^{a}$ \\
\hline NC+Vit. C & 783.7 & 1169 ab & $1953^{a}$ & 1309 & 2541 & 3850 & $1.67^{b}$ & $2.17 \mathrm{bc}$ & $1.97 \mathrm{bc}$ \\
\hline $\mathrm{NC}+\mathrm{CoQ}_{10}$ & 737.3 & 1168 ab & 1906 ab & 1258 & 2476 & 3734 & $1.71^{b}$ & $2.12^{c}$ & $1.96^{c}$ \\
\hline $\mathrm{NC}+$ Vit. $\mathrm{C}+\mathrm{CoQ}_{10}$ & 740.4 & 1179 a & 1920 ab & 1301 & 2569 & 3870 & $1.76^{b}$ & $2.18^{b c}$ & $2.01 \mathrm{bc}$ \\
\hline SEM & 17.5 & 27.1 & 36.6 & 36.1 & 47.0 & 53.7 & 0.04 & 0.05 & 0.03 \\
\hline$p$-Value & ns & 0.001 & 0.002 & ns & ns & ns & 0.006 & 0.001 & 0.001 \\
\hline Orthogonal contrasts & & & & & -Values & & & & \\
\hline PC vs. NC & ns & 0.05 & ns & 0.02 & ns & 0.03 & 0.006 & 0.003 & 0.001 \\
\hline NC vs. Antioxidant & ns & 0.001 & 0.002 & 0.04 & ns & ns & 0.005 & 0.001 & 0.001 \\
\hline PC vs. Antioxidant & ns & 0.02 & 0.01 & ns & ns & ns & ns & ns & ns \\
\hline \multicolumn{10}{|c|}{ Main effects and interactions } \\
\hline Vit. C & ns & 0.008 & 0.008 & ns & ns & ns & 0.04 & 0.01 & 0.002 \\
\hline CoQ10 & ns & 0.009 & ns & ns & ns & ns & ns & 0.001 & 0.008 \\
\hline Vit. $\mathrm{C} \times \mathrm{CoQ} 10$ & ns & 0.02 & 0.02 & ns & ns & ns & 0.003 & 0.008 & 0.001 \\
\hline
\end{tabular}

Means with different superscripts in the same column are significantly different $(p<0.05)$.

BWG, body weight gain; FI, feed intake; FCR, feed conversion ratio.

PC, positive control; NC, negative control; Vit. C, vitamin $C_{;} C_{0} Q_{10}$ Coenzyme $Q_{10}$

Antioxidant treatments include mean of Vit. $\mathrm{C}, \mathrm{CoQ}_{10}$ and $\mathrm{Vit} . \mathrm{C}+\mathrm{CoQ}_{10}$ groups.

$(p<0.01)$, but no synergism was observed between Vit. $C$ and $C_{0 Q}$.

\section{Thyroid hormones}

Thyroxin $\left(T_{4}\right)$ levels and triiodothyronine $\left(T_{3}\right)$ to thyroxin ratio were affected $(p<0.05)$ by treatments (Table 4). The PC group presented the highest $T_{4}$ level and the lowest $T_{3} / T_{4}$ ratio. The antioxidant addition increased plasma $\mathrm{T}_{4}$ and reduced $T_{3} / T_{4}$ ratio relative to $N C$, although, this difference was not significant. Plasma $T_{3}$ was not affected by treatments.

Table 3 - Effect of vitamin $\mathrm{C}$ and $\mathrm{CoQ}_{10}$ on ascites indices and red blood cell characteristic of broilers under cold stress

\begin{tabular}{|c|c|c|c|c|c|c|}
\hline \multirow{2}{*}{ Variable } & \multicolumn{3}{|c|}{ ascites indices } & \multicolumn{3}{|c|}{ RBC parameter } \\
\hline & Ascites mortality (\%) & Heart (\%BW) & $\mathrm{RV} / \mathrm{TV}(\%)$ & $\mathrm{RBC} \times 10^{6}$ & $\mathrm{PCV}(\%)$ & $\mathrm{Hb}(\mathrm{gr} / \mathrm{dl})$ \\
\hline PC & $12.62^{b}$ & 0.59 & 25.1 & $2.32^{b c}$ & $29.85^{b c}$ & $11.62^{b}$ \\
\hline NC & $20.02^{a}$ & 0.66 & 27.2 & $2.65^{a}$ & $35.02^{\mathrm{a}}$ & $13.55^{\mathrm{a}}$ \\
\hline NC+Vit. C & $13.68^{b}$ & 0.63 & 24.9 & $2.17^{c}$ & $28.06^{c}$ & $11.46^{b}$ \\
\hline $\mathrm{NC}+\mathrm{CoQ}_{10}$ & $11.56^{b}$ & 0.60 & 25.5 & $2.53^{a b}$ & 32.31 ab & $12.90^{\mathrm{a}}$ \\
\hline $\mathrm{NC}+$ Vit. $\mathrm{C}+\mathrm{CoQ}_{10}$ & $18.96^{a}$ & 0.62 & 25.2 & $2.44^{a b}$ & $32.18^{\mathrm{ab}}$ & $12.82^{\mathrm{a}}$ \\
\hline SEM & 1.60 & 0.03 & 0.65 & 0.08 & 1.15 & 0.37 \\
\hline$p$-Value & 0.003 & ns & ns & 0.002 & 0.001 & 0.003 \\
\hline orthogonal contrasts & \multicolumn{6}{|c|}{$p$-Value } \\
\hline PC vs. NC & 0.004 & ns & 0.03 & 0.006 & 0.002 & 0.002 \\
\hline NC vs. Antioxidant & 0.01 & ns & 0.01 & 0.001 & 0.003 & 0.02 \\
\hline PC vs. Antioxidant & ns & ns & ns & ns & ns & ns \\
\hline \multicolumn{7}{|c|}{ Main and interaction effects } \\
\hline Vit. C & ns & ns & 0.05 & 0.001 & 0.003 & 0.007 \\
\hline CoQ10 & ns & ns & ns & ns & ns & ns \\
\hline Vit. $C \times C o Q 10$ & 0.008 & ns & ns & 0.02 & 0.005 & 0.01 \\
\hline
\end{tabular}

Means with different superscripts in the same column are significantly different $(p<0.05)$.

$\mathrm{RV} / \mathrm{TV}$, right ventricular/total ventricular

PC, positive control; NC, negative control; Vit. C, vitamin $C ; C_{0} Q_{10}$ Coenzyme $Q_{10}$

Antioxidant treatments include mean of Vit. $\mathrm{C}, \mathrm{CoQ}_{10}$ and Vit. $\mathrm{C}+\mathrm{CoQ}_{10}$ groups. 
Table 4 - Effect of vitamin $C$ and $\operatorname{CoQ}_{10}$ on thyroid hormones of broilers under cold stress

\begin{tabular}{lccc}
\hline Variable & $\mathrm{T}_{3}(\mathrm{ng} / \mathrm{mL})$ & $\mathrm{T}_{4}(\mathrm{ng} / \mathrm{mL})$ & $\mathrm{T}_{3} / \mathrm{T}_{4}$ \\
\hline $\mathrm{PC}$ & 1.12 & 8.75 & 0.13 \\
$\mathrm{NC}$ & 1.50 & 4.75 & 0.33 \\
$\mathrm{NC}+$ Vit. C & 1.40 & 5.33 & 0.26 \\
$\mathrm{NC}+\mathrm{CoQ}_{10}$ & 1.37 & 6.25 & 0.23 \\
$\mathrm{NC}+$ Vit. C+CoQ 10 & 1.43 & 6.50 & 0.24 \\
$\mathrm{SEM}$ & 0.23 & 1.03 & 0.05 \\
p-Value & $\mathrm{ns}$ & $\mathrm{ns}$ & $\mathrm{ns}$ \\
Orthogonal contrasts & & $p$-Value & \\
PC vs. NC & 0.01 & 0.01 & 0.02 \\
NC vs. Antioxidant & $\mathrm{ns}$ & $\mathrm{ns}$ & $\mathrm{ns}$ \\
PC vs. Antioxidant & 0.03 & 0.05 & 0.02 \\
Main effects and interactions & & & \\
Vit. C & $\mathrm{ns}$ & $\mathrm{ns}$ & $\mathrm{ns}$ \\
CoQ10 & $\mathrm{ns}$ & $\mathrm{ns}$ & $\mathrm{ns}$ \\
Vit. CxCoQ10 & $\mathrm{ns}$ & $\mathrm{ns}$ & $\mathrm{ns}$ \\
\hline
\end{tabular}

Means with different superscripts in the same column are significantly different $(p<0.05)$.

$P C$, positive control; $N C$, negative control; Vit. $C$, vitamin $C_{;} \mathrm{CoQ}_{10^{\prime}}$ Coenzyme $Q_{10}$ Antioxidant treatments include mean of Vit. $C, C_{0} Q_{10}$ and Vit. $C+C o Q_{10}$ groups.

\section{DISCUSSION}

The results indicated that NC birds presented worse performance reduced due to cold stress, which was in agreement with several studies (Mendes et al., 1997; Hangalapura, 2003; Blahova et al., 2007; Ipek \& Sahan, 2006; Balog et al., 2003). Cold stress increases the energy requirement for thermoregulation, diverting the available energy for production to maintenance (Hangalapura et al., 2003). Cold-exposed broilers also increase their $\mathrm{Fl}$ to increase the thermogenic effect of nutrient absorption, assimilation, and utilization (McKee et al., 1997; Collin et al., 2003). Under low environmental temperatures, the activity of the thyroid increases, resulting in high metabolic rate, oxygen consumption, and $\mathrm{Fl}$ for thermoregulation, which may lead to reduced BWG. The result of present study clearly showed that broilers fed diets with the individual supplementation of Vit. $\mathrm{C}$ or $\mathrm{CoQ}_{10}$ presented better performance than the NC birds, but no synergism was observed between these two antioxidants. The effectiveness of Vit. $C$ to improve the performance of broilers under stress was previously demonstrated (Walton, et al., 2001; Ruiz-Feria et al., 2001, 2009). This may be explained by the different roles of Vit. C in the body. Ascorbic acid is required for the synthesis of collagen, carnitine, corticosterone, and several neurotransmitters. It is also involved in the metabolism of tyrosine, iron, and thyroid hormones. More importantly, it is a powerful antioxidant and its ability to protect lipids against peroxidation in plasma is higher than vitamin E (McDowell, 2000). Vit. C is not regarded as a dietary requirement for poultry because it has been postulated that it can be synthesized at a sufficient rate to meet the needs under normal rearing conditions. However, there are evidences of lower endogenous Vit. C production in young relative to adult broilers (Leeson \& Summers, 2001).

$\mathrm{CoQ}_{10}$, as a necessary component of the respiratory chain in the inner mitochondrial membrane, not only functions as an electron and proton carrier and drives ATP synthesis, but its reduced form $\left(\mathrm{CoQH}_{2}-\right.$ ubiquinol) may act as an important antioxidant to reduce the accumulation of free radicals, particularly of ROS, and alleviate the peroxidative damage to the body. It can also act as a non-specific stimulant of immune host defense system (Geng et al., 2007). The observed growth-promoting effect of $\mathrm{CoQ}_{10}$ under ascites-inducing conditions in the present study was comparable with the results of Nakamura et al. (1996) and Geng et al. (2004).

\section{Ascites indices}

The experimental procedure was successful to induce ascites, as shown by the highest mortality rate due to ascites of NC birds. Cold temperatures increase the incidence of ascites by increasing both metabolic oxygen requirements and pulmonary hypertension (Bendheim et al., 1992; Julian et al., 1989; Stolz et al., 1992). Oxidative stress due to increased ROS production from mitochondrial electron leak is one of the main causes of the etiology of ascites in poultry exposed to cold temperatures (Currie, 1999). In the present study, mortality due to ascites and the RV/TV ratio in the groups supplemented with Vit. $C$ or $\mathrm{CoQ}_{10}$ were reduced to comparable PC levels, which indicates the significant role of these anti-oxidative substances in the occurrence of ascites (Geng et al., 2004).

Our findings are consistent with those of Nakamura et al. (1996) and Geng et al. (2004), who showed that dietary $\mathrm{Q}_{9}$ or $\mathrm{Q}_{10}$ supplementation, respectively, was effective in reducing the incidence of ascites in broilers. Those authors suggested that $\mathrm{CoQ}_{10}$ protects cardiac myocytes by supplying enough energy, in the form of ATP, for the cardiac muscle. Ubiquinol, the reduced form of $\mathrm{CoQ}_{10}$, can function as an antioxidant in blood to protect the erythrocyte membrane structure, increase their deformability and transportation ability, and hence, reduce mortality due to ascites (Geng et al., 2004).

Red blood cell counts, PCV values and hemoglobin levels were significantly increased in NC birds and reduced by Vit. C supplementation. These findings are consistent 
Cold-Induced Ascites in Broilers: Effects of Vitamin C and Coenzyme $Q_{10}$ with the Blahva et al. (2007), Yahav (1999), Ipek \& Sahan (2006). Under low environmental temperatures, broilers are forced to increase their metabolic rate. More erythrocytes are needed to transport oxygen to meet these increased metabolic needs. The increased oxygen requirement leads to physiological hypoxia, stimulation of erythropoiesis, and eventually increased hematocrit values (Gupta, 2011).

Dietary Vit. C addition returned RBC counts to the normal levels. Continuous increase in corticosterone levels in ascitic chickens resulted in increased production of red blood cells (Baghbanzadeh \& Decuypere, 2008). Supplemental Vit. C may reduce plasma corticosterone. A likely mechanism is inhibited by $\mathrm{C}-21$ hydroxylase and 11-b hydroxylase and decreased corticosterone synthesis (McKee et al., 1997).

\section{Thyroid Hormones}

The dietary supplementation of Vit. C significantly reduced the mortality due to ascites in broilers, with a concomitant reduction in plasma thyroid hormone levels, suggesting a role of Vit. C in metabolic activity (Hassanzadeh et al., 1997).

Cold stress induces physiological changes that are of high priority and energy demanding in homeotherms. Cold stress alters the function of hypothalamic-pituitarythyroid and adrenal axis, resulting in changes in the circulating levels of thyroid and adrenal hormones. Cold environmental temperatures increase the levels of $T_{3}$, which is required for the generation of additional metabolic heat to maintain body temperature in cooler environments. The subsequent increase in metabolic rate results in an increase in blood pressure as the heart attempts to maintain the oxygen supply to the organs and muscles, thus leading to pulmonary hypertension, right ventricular failure, and eventually ascites (Julian et al., 1989; Acar et al., 1995; Gupta, 2011).

In conclusion, the production of free radicals in cold stress conditions destroy cell membranes, especially of erythrocytes, changes the circulating levels of thyroid and adrenal hormones, increasing the metabolic rate and the energy requirement for maintenance of broilers, which results in worse performance. Vitamin $\mathrm{C}$ and $\mathrm{CoQ}_{10}$ function as antioxidants. Therefore, the supplementation of Vit. C or $\mathrm{CoQ}_{10}$ in the diet of broiler chickens under cold stress conditions improves their performance parameters (body weight and FCR) and ascites-related traits (low red blood cell count, hematocrit, $T_{3}$, and heart weights, and elevated $T_{4}$ ). No significant improvements in these parameters were observed with the combination of Vit. C and $\mathrm{CoQ}_{10}$ relative to their individual application.

\section{REFERENCES}

Acar N, Sizemore FG, Leach GR, Wideman JR, Owen RL, Barbolo GF. Growth of broiler chickens in response to feed restriction regimens to reduce ascites. Poultry Science 1995;74:833-843.

Al-Taweil RN, Kassab A. Effect of dietary vitamin C on Ascites in broiler chikes. PubMed 1990;60(4):366-371

Baghbanzadeh A, Decuypere E. Ascites syndrome in broilers: physiological and nutritional perspectives. Avian Pathology 2008;37:117-126.

Balog JM, Kidd BD, Huff WE, Huff JR, Rath NC, Anthony NB. Effect of cold stress on broilers selected for resistance or susceptibility to ascites syndrome. Poultry Science 2003;82:1383-1387.

Bendheim U, Berman E, Zadikov I. The effects of poor ventilation, low temperatures, type of feed and sex of bird on the development of ascites in broilers. Production parameters. Avian Pathology 1992;21(3):383388.

Blahova J, Dobsikova R, Strakova E, Suchy P. Effect of low environmental temperature on performance and blood system in broiler chickens (Gallus domesticus). Acta Veterinaria Brno 2007;76:S17-S23.

Bottje WG, Wideman RF. Potential role of free radicals in the pathogenesis of pulmonary hypertension syndrome. Poultry Avian Biology Review $1995 ; 6: 221-231$

Collin A, Buyse J, AS PV, Darras VM, Malheiros RD, Moraes VMB, et al. Cold-induced enhancement of avian uncoupling protein expression, heat production, and triiodothyronine concentrations in broiler chicks. General and Comparative. Endocrinology 2003;130(1):70-77.

Currie RJW. Ascites in poultry: recent investigations. Avian Pathology $1999 ; 28: 313-326$

Dawson YL, Gores GL, Nieminen AL. Mitochondria as a source of reactive oxygen species during reductive stress in rats hepatocytes. American Journal of Physical Anthropology 1993;264:C961-967.

Enkyetchakul B, Bottje W, Anthony N, Moore R, Huff W. Compromised antioxidant status associated with ascites in broilers. Poultry Science $1993 ; 72: 2272-2280$

Forsmark-Andre'EP, Lee CP,Dallner G,Ernster L. Lipid peroxidation and changes in the ubiquinone content and the respiratory chain enzymes of sub mitochondrial particles. Free Radical Biology and Medicine 1997;22:391-400.

Geng AL, Baoming L, Yuming G. Effects of dietary L-carnitine and coenzyme Q10 at different supplemental ages on growth performance and some immune response in ascites-susceptible broilers. Archives of Animal Nutrition 2007;61(1):50 - 60 .

Geng AL, Guo YM, Yang Y. Reduction of ascites mortality in broilers by voenzyme Q10. Poultry Science 2004;83:1587-1593.

Gupta AR. Ascites syndrome in poultry: a review. World Poultry Science Journal 2011;67:457-468

Hangalapura BN, Nieuwland MGB, De Vires Reilingh G, Heetkamp MJW Van Den Brand $H$, Kemp $B$, et al. Effect of cold stress on immune responses and body weight of chickens lines divergently selected for antibody responses to sheep red blood cells. Poultry Science 2003;82:1692-1700.

Hassnzadeh M, Buys N, Dewil E, Rahimi G, Decuypere E. The prophylactic effect of vitamin $C$ supplementation on broiler ascites incidence and plasma thyroid hormone concentration. Avian Pathology 1997;26:3344.

IpekA, Sahan U. Effects of cold stress on broiler performance and ascites susceptibility. Journal of. Animal Science 2006;5:734-738. 
Nemati MH, Shahir MH,

Harakinezhad MT, Lotfalhian H
Cold-Induced Ascites in Broilers: Effects of Vitamin C

and Coenzyme $Q_{10}$
Julian RJ. Lung volume of meat-type chickens. Avian Diseases 1989;33:174176.

Leeson S, Summers JD. Scott's nutrition of the chicken. Guelph: University Books; 2001.

McDowell, L. R. Vitamins in animal and human nutrition. 2nd ed. Ames: lowa State University Press; 2000.

McKee JC, Harrison PC, Riskowski GL. Effects of supplemental ascorbic acid on the energy conversion of broiler chicks during heat stress and feed withdrawal. Poultry Science 1997;76:1278-1286.

Mendes AA, Watkins SE, England JA, Saleh EA, Waldroup AL, Waldroup PW. Influence of dietary lysine levels and arginine:lysine ratios on performance of broilers exposed to heat or cold stress during the period of three to six weeks of age. Poultry Science 1997;76:472-481.

Nakamura K, Noguchi K, Aoyama T, Nakajlma T, Tanimura N. Protective effect of ubigunone ( coenzyme Q9) on ascites in broiler chickens. British Poultry Science 1996;37:189- 195.

Ruiz-Feria CA. Concurrent supplementation of arginine, vitamin E, and vitamin $C$ improve cardiopulmonary performance in broilers chickens. Poultry Science 2009;88:526-535

Ruiz-Feria, CA, Kidd MT, Wideman RF. Plasma levels of arginine, ornithine, and growth performance of broilers fed supplemented l-arginine during cool temperature exposure .Poultry Science 2001;80:358-369.
SAS. SAS/STAT Software: chang and enhancement through release 9.1 Cary: SAS Institute; 2002-2003.

Shahir MH, Dilmagani S, Tzschentke B. Early-age cold conditioning of broilers: effects of timing and temperature. British Poultry Science 2012;53:538-544.

Shinder D, Luger D, Rusal M, Rzepakovsky V, Bresler V, Yahav S. Early age cold conditioning in broiler chickens (Gallus domesticus): thermotolerance and growth responses. Journal of Thermal Biology 2002;27:517-523.

Stolz JL, Rosenbaum LM, Jeong D, Odom TW. Ascites syndrome, mortality and cardiological responses of broiler chickens subjected to cold exposure. Poultry Science 1992;71:1-4.

Tang Z, Iqbal M, Cawthon D, Bottje WG. Heart and muscle itochondrial dysfunction in pulmonary hypertension syndrome in broilers (Gallus domesticus) Comparative Biochemistry and Physiology 2002;132:527540 .

Walton JP, Julian RJ, Squires EJ. The effects of dietary flax oil and antioxidants on ascites and pulmonary hypertension in broilers using a low temperature model. British. Poultry Science 2001;42:123-129.

Yahav S. The effect of constant and diurnal cyclic temperatures on performance and blood system of young turkeys. Journal Thermal Biology 1999;24:71-78. 
